\title{
Bullous impetigo caused by Streptococcus salivarius: a case report
}

\author{
ITZHAK BROOK \\ From the Department of Infectious Diseases and Clinical Microbiological Laboratory, Children's \\ Hospital National Medical Center and George Washington School of Medicine, Washington, DC, USA
}

SUMMARY A 19-month-old child presented with bullous impetigo around the perineal region, penis, and left foot. Streptococcus salivarius was the only isolate recovered from the lesions. The child was treated with parenteral penicillin, debridement of the bulli, and local application of silver sulphadiazine cream. This case of bullous impetigo illustrates another aspect of the pathogenicity of Strep. salivarius.

Streptococcal pyoderma or impetigo is a common problem in children. The infection usually begins with an outbreak of vesicular lesions on the arms and legs and on occasion they are seen around the nose, mouth, and scalp. The blisters are usually flat and contain clear fluid, which usually yields a pure culture of group A beta-haemolytic streptococci and, rarely, group C or G. ${ }^{1}$

This is a report of a 19-month-old child who presented with bullous impetigo. The organism recovered from the bullous fluid was Streptococcus salivarius, found in the normal mouth flora. ${ }^{2} 3$ Although this organism has been isolated from patients with endocarditis, sinusitis, mastoiditis, cholangitis, peritonitis, pneumonia, and meningitis $^{4-6}$ it has never been recovered from bullous impetigo.

\section{Case report}

A 19-month-old black boy was admitted to Children's Hospital National Medical Center for the treatment of watery blisters around the penis, perineal area, and the dorsal area of the foot. These lesions appeared two days before admission and were accompanied by a temperature up to $38^{\circ} \mathrm{C}$. Past medical and family histories revealed no abnormalities. Physical examination showed a child in moderate distress, pulse $136 / \mathrm{min}$, temperature $38.6^{\circ} \mathrm{C}$, and respiration $40 /$ minute. Several blisters filled with light yellow liquid were observed around the perineal region, the glans and shaft of the penis, and the left heel and foot. The diameter of the blisters was 3-9 cm (Figs 1 and 2). Lymph nodes

Received for publication 25 March 1980 were enlarged in both inguinal areas. The rest of the physical and neurological examinations were normal. Admission laboratory data showed a haemoglobin of $12.9 \mathrm{~g} / \mathrm{dl}$, haematocrit $38 \%$, white blood cells $11.2 \times 10^{9} / 1\left(11200 / \mathrm{mm}^{3}\right)$ with $54 \%$ segmented neutrophils, $24 \%$ lymphocytes, $18 \%$ monocytes, $2 \%$ eosinophils, and $2 \%$ bands. Urinalysis was normal and blood cultures were negative.

The large bulli were aspirated and debrided, and their contents were sent for culture for aerobic and anaerobic bacteria and viruses. Cultures of vesicular fluid obtained from two vesicles by direct needle aspiration (the left foot and the perineal region) yielded a pure growth of an alpha-haemolytic streptococcus, which was identified by the Center for Disease Control as Strep. salivarius. Biopsy of the lesion demonstrated the presence of intraepidermal bulli containing Gram-positive cocci in chains and proteinaceous material, many neutrophils, and a few lymphocytes. Some of the bulli that were not aspirated persisted for 7 to 10 days. Treatment was started with the local application of silver sulphadiazine cream (Silvadene) and Phisohex soap baths and parenteral crystalline penicillin 100000 units/kg per day for seven days. The patient responded well to therapy, and the denuded area showed slow epithelialisation and complete healing of the skin within two weeks.

\section{Discussion}

Current evidence suggests that impetigo can be divided on clinical and bacteriological grounds into two basic forms: a bullous type, which ultimately forms thin, varnish-like crusts and is primarily staphylococcal in origin, and a vesicular type, which 


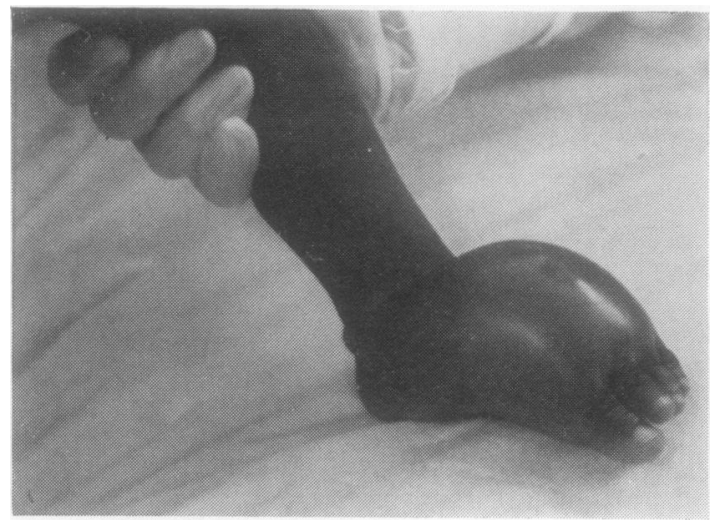

Fig. 1 Bullous lesion of left foot.

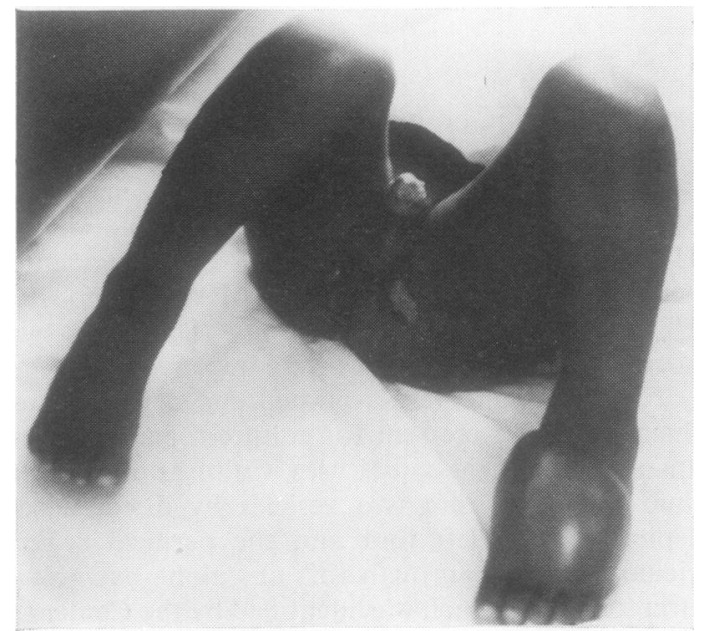

Fig. 2 Bullous lesions in perineum and on left foot.

develops thick 'stuck-on' crusts and is primarily streptococcal in aetiology. ${ }^{7}$ The relative frequency of these two kinds of impetigo varies from place to place and from time to time. ${ }^{7-9}$

The initial lesion of streptococcal impetigo is a tiny papule. A vesicle filled with serous fluid and a few leucocytes rapidly forms and is surrounded by a narrow rim of erythema. The blisters are flat, with a diameter of 1 to $3 \mathrm{~mm}$. The clear fluid of such a vesicle usually yields a pure culture of group A streptococci. The vesicles rapidly become pustular, and the fluid can infect by direct extension other areas, where new vesicles form. All these vesicles soon break, and the surface becomes covered by a thick, hard, brownish 'candy' crust, which is characteristic of streptococcal impetigo. Although the final lesions may be as large as $3 \mathrm{~cm}$ in diameter, they remain discrete. The lesions may later become secondarily infected by staphylococci which are present on normal skin.

Staphylococcal impetigo is characterised by persistent bullous lesions, which subsequently form thin, varnish-like crusts which may be white or grey in colour. The bullous form of impetigo usually yields pure cultures of phage type 71 staphylococci or closely related strains. ${ }^{10} 11$

It is of interest that our patient developed bullous lesions, which were microscopically and clinically similar to staphylococcal impetigo, whereas the lesions persisted for many days without spontaneous rupture. However, the only organism recovered was Strep. salivarius. Strep. salivarius is usually found in the mouth and throat. Several investigators have observed high levels of this organism on the dorsum of the tongue and in saliva but low levels in dental plaque. $^{2} 3$

Strep. salivarius belongs to the group of poorly defined viridans streptococci. Differentiation of this organism may be best achieved by its physiological characteristics, ${ }^{5}$ although a number of strains of Strep. salivarius show reactions with Lancefield group $\mathrm{K}$ antiserum.

As indicated by sensitivity tests and clinical response, penicillin $\mathrm{G}$ is the antibiotic of choice in treating infections due to Strep. salivarius. ${ }^{4}$ These organisms are sensitive to the majority of antibiotics except aminoglycosides and tetracycline. Specific differentiation of viridans streptococci by biochemical and serological means should provide a better appreciation of the pathogenicity, antimicrobial susceptibility, and epidemiology of this heterologous group of microorganisms.

\section{References}

${ }^{1}$ Wannamaker LW. Differences between streptococcal infection of the throat and the skin. New Eng J Med 1970;282:23.

${ }^{2}$ Gibbons RJ, Kapsimalis B, Socransky SS. The source of salivary bacteria. Arch Oral Biol 1964;9:101.

${ }^{3}$ Krasse B. The proportional distribution of Streptococcus salivarius and other streptococci in various parts of the mouth Odontol Rev 1954;5:203.

${ }^{4}$ Duma RJ, Weinberg AN, Medrek TF et al. Streptococcal infections: A bacteriologic and clinical study of streptococcal bacteremia. Medicine 1969;48:87.

${ }^{5}$ Facklam RR. Physiological differentiation of viridans streptococci. J Clin Microbiol 1977;5:184.

- Wheeler SM, Foley GE. A note on non-group A streptococci associated with human infection. J Bact 1943; 46:391.

${ }^{7}$ Parker MT, Williams REO. Further observations on the bacteriology of impetigo and pemphigus neonatorum. Acta Paediat 1961;50:101.

${ }^{8}$ Engman MF. Contagiosa bullosa and its bacteriology. J Cut Gen-Urin Dis 1901;19:180.

${ }^{9}$ Tachau P. The bacteriology of impetigo contagiosa. Brit J Dermat 1938;50:113.

${ }^{10}$ Spittlehouse KE. Phage-types of staphylococcus pyogenes 
isolated from impetigo and sycosis barbae. Lancet $1955 ; 2: 378$.

11 Van Toorn MJ. On the staphylococcal and streptococcal etiology of impetigo. Dematologica (Basel) 1961; 123:391.

\section{The October 1980 Issue}

\section{THE OCTOBER 1980 ISSUE CONTAINS THE FOLLOWING PAPERS}

Review article

Cobalamins and nitrous oxide: a review I CHANARIN

Monocytes in inflammatory bowel disease: absolute monocyte counts AS MEE, J BERNEY, AND DP JEWELL

Monocytes in inflammatory bowel disease: phagocytosis and intracellular killing AS MEE, M SZAWATAKOWSKI, AND DP JEWELL

Processing haematological data on a dedicated computer MG NELSON, CL FARRINGTON, JD ROGERS, AND GW PURDY

Immunochemical and ultrastructural study of multiple myeloma with a heavy chain protein in the serum C BARTOLINI, G FLAMINI, N GENTILONI, MA RUSSO, C BARONE, G GAMBASSI, AND T TERRANOVA

Haematological characteristics in the $\beta^{0}$ thalassaemia trait in Sardinian children $R$ GALANELlo, $S$ DE VIRGILIIS, M ADDIS, E PAGLIETTI, R RUGGERI, AND A CAO

Chronic liver disease in transfusion-dependent thalassaemia: hepatitis $B$ virus marker studies S DE VIRGILIIS, G FIORELLI, S FARGION, G CORNACCHIA, G SANNA, P COSSU, V MURGIA, AND A CAO

Anti-A haemagglutinins in factor VIII concentrates JK SMITH, PJ BOWELL, E BIDWELL, AND HH GUNSON

Evaluation of an AutoAnalyzer method for quantitating anti-A and anti-B haemagglutinins in factor VIII preparations PJ BOWELL, S ABDALLA, TJ SNAPE, AND HH GUNSON

Platelet monoamine oxidase activity in megaloblastic anaemia V GLOVER, M SANDLER, A HUGHES, AND AV HOFFBRAND

Vitamin $\mathbf{D}$ binding globulin levels and affinity in various clinical conditions IRF BROWN, ANITA SOOD AND ND CARTER
Requests for reprints to: Itzhak Brook, MD, MS Infectious Disease and Clinical Microbiology Laboratory Children's Hospital National Medical Center, 111 Michigan Avenue, NW, Washington DC, 20010, USA.
Familial hypouricaemia associated with renal tubular uricosuria and uric acid calculi : case report JM HEDLEY AND PJ PHILLIPS

Determination of plasma malondialdehyde-like material and its clinical application in stroke patients MT SANTOS, J VALLES, J AZNER, AND J VILCHES

Quantitation of C3 subcomponents on red cells coated with complement in vitro J FREEDMAN AND ANNE MASSEY

Spontaneous calcific embolisation: necropsy $X$-ray study I STEINER AND A HLAVA

Serial urinary and cervical cytological studies in women undergoing renal transplantation $\mathrm{CJH}$ INGOLDBY, NA MCWHINNEY, E WACHTEL, AND JE CASTRO

False negative hepatitis B surface antigen detection in dialysis patients due to excess surface antigen: postzone phenomenon LG HEFTER, MARY A HIX, MICHELLE STONER, AND CB COOK

Light-scattering methods for antibiotic sensitivity tests J MURRAY, P EVANS AND DWL HULKINS

Antimicrobial susceptibilities of Clostridium difficile R SHUTTLEWORTH, MILDRED TAYLOR, AND DM JONES

Faecal carriage of group B streptococci AKMS ISLAM AND ELIZABETH THOMAS

\section{Technical methods}

A systematic error in pH-stat assays of enzymes in haemolysates PFJ NEWMAN AND IA NIMMO

Fixation and immunohistochemistry of lymphoid tissue A LEATHEM AND N ATKINS

\section{Letters to the Editors}

Book reviews

Copies are still available and may be obtained from the PUBLISHING MANAGER, BRITISH MEDICAL ASSOCIATION, TAVISTOCK SQUARE, LONDON WC1H 9JR, price $£ 3.00$, including postage 